\title{
New Generation Rotary Drill Bits: Klaw Bit Performance Analysis and Compared with Tricone Bit
}

\author{
Bahadır Ergener ${ }^{1}$, Deyvi Akkriş ${ }^{2}$, Curtis Larson ${ }^{3}$, Ömür Acaroğlu ${ }^{4}$, Hasan Ergin ${ }^{5}$, Ufuk Çalışkan ${ }^{6}$, Melis \\ Toker $^{7}$ \\ ${ }^{1,2,3}$ Atlas Copco Turkey \\ Istanbul, Turkey \\ bahadir.ergener@atlascopco.com.tr; deyvi.akkris@tr.atlascopco.com; curtis.larson@us.atlascopco.com \\ 4, 5, 6, 7 Istanbul Technical University, Department of Mining Engineering, \\ Ayazaga Campus, Mining Faculty, Mining Engineering Department, 34469 Maslak/Istanbul \\ acaroglu@itu.edu.tr; hergin@itu.edu.tr; tokermelis@itu.edu.tr
}

\begin{abstract}
In open pit mining, drilling of blasting holes is a long and costly process. Selection of optimum bit for a formation is the most important parameter in rapid and economic drilling process. Although theoretical and experimental studies are common, the best way of choosing the most appropriate rock bit for a region is the usage of the bits directly on the machines. The aim of this study is to determine and compare performance of classical tricone bit and klaw which is new product in rotary drilling. For this reason, drilling speeds of both bits were measured in four benches having different geological properties in an open pit lignite mine that belongs to Demir Export. As comparing drilling speed of bits, klaw bit is 2,8 times rapid than tricone bit in hard formation and between 1,5 and 2,5 times rapid in soft formation. Furthermore, replaceable teeth of klaw bit has advantage of continuing long time drilling without changing main body of it. Having longer life and higher drilling speed prove that klaw bits are important alternative bit for rotary drilling on economic aspect.
\end{abstract}

Keywords: rotary drilling, tricone bits, klaw bits, performance analysis

\section{Introduction}

In the drilling process with drilling machines, maximum consumption is caused by bits that contact continuously with rock whose physical, mechanical and mass properties effect on abrasion of bits. Drilling costs and effective drilling time is increased, due to the frequent change [1,2]. Drill bit production is limited in Turkey, usually obtained from abroad and costs can become too high [3].

In order to effective blasting operation, explosives which used must distributed homogeneously into the rock, therefore a certain holes are drilled by drilling machines in open pit mines. Diameter holes can be classified as large, medium and small and machines and drilling machines can be classified as rotary, down the hole hammer and top hammer according to working principles [4-6].

Rotary drilling machine which is used in 1845 first and then rapid developments have continued until today. Conical bits especially having three cones named tricone bits are most common used in this machine and they are usually suitable for medium and hard rocks [2,4-6]. For softer formation drag type bits can be used, but they are not common. Type and design of the tricone bits can generally be selected considering IADC (International Association of Drilling Contractors) classification. Tricone bits are almost only one alternative for the rotary drilling, because of resistance to abrasion [2,4-6]. Researches have been continued estimating performance prediction of this bit considering rock mechanical and mass properties [7-12]. However, new alternative bits to tricone bits have been developed in recent years. One of them is klaw bit whose head is manufactured as two parts; cutting teeth and a cutter holding these teeth. When deformation occurs some of these teeth, they can be replaced new ones, so without changing entire bit, it can be used for a long time $[13,14]$.

The aim of this study is to select fastest and most durable bit for an open pit lignite mine in the Kangal town of Sivas in Turkey, by measuring the speed of the bits in the field. Select the most appropriate bit will directly reduce the cost of consumption and increase the drilling performance. 


\section{Properties of the Studied Field}

Demir Export, a mining company, produces coal in an open pit mine located in Kangal Town of Sivas County in Turkey for Kangal Thermic Power Plant (Fig. 1). The power plant is designed to assess the lignite coal with 2x150 MW capacity. Coal mines and power plant were established to evaluate a 170 million tons of coal in the vicinity of Sivas county as named Kangal, Hamal, Kangal, Hamal, Kalburçayırı, Şekerpınar and Turnali [15].

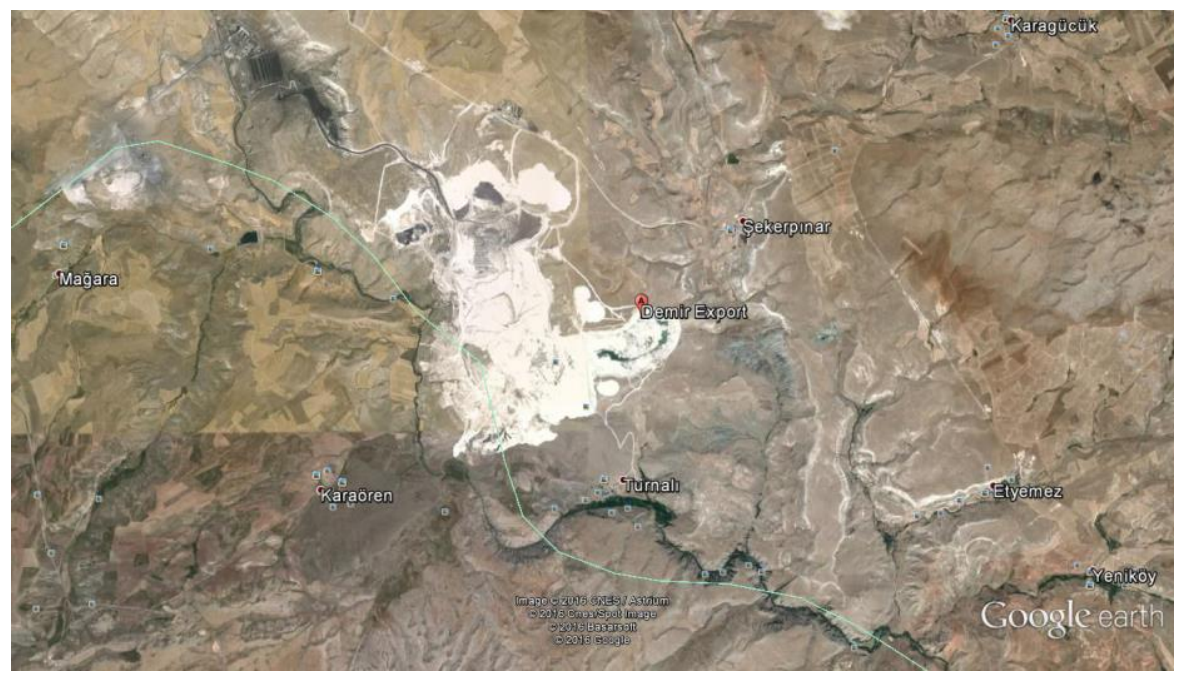

Fig. 1: Satellite image of Demir Export.

Overburden removal works in the mine are usually carried out with draglines, excavators and trucks. Capacity of trucks are 32, 40 and $100 \mathrm{~m}^{3}$ and draglines removes material about $30000 \mathrm{~m}^{3}$ and excavators are operated as diesel or electric with the capacity of 8 or $19 \mathrm{~m}^{3}$. Overall slope angle of the pit is about $24^{0}$, slope angle of the benches are $70-80^{\circ}$ and there are four benches. With the width of 20-40 m and the height of about $14 \mathrm{~m}$. There are two coal seams changing thickness between 3 and $5 \mathrm{~m}$ including a clay tuffite layers [15].

Coal production and stack lift is carried out in four different stairs. Stack is loaded with $7.65-19 \mathrm{~m}^{3}$ excavators after drilling and blasting process. Stair width varies between 20-40 meters in the upper pit level. The top pit level is the same as the land height. Studied area in Kalburcayiri formation was classified into two different series with including gravel or lignite. The series including lignite replaces on the series including gravel. Its thickness is between 25-60 m and starts with silt and clay and continues with coal, clay and marn. There are two coal seam and called lower and upper seams that is given in Figure $2[15]$.

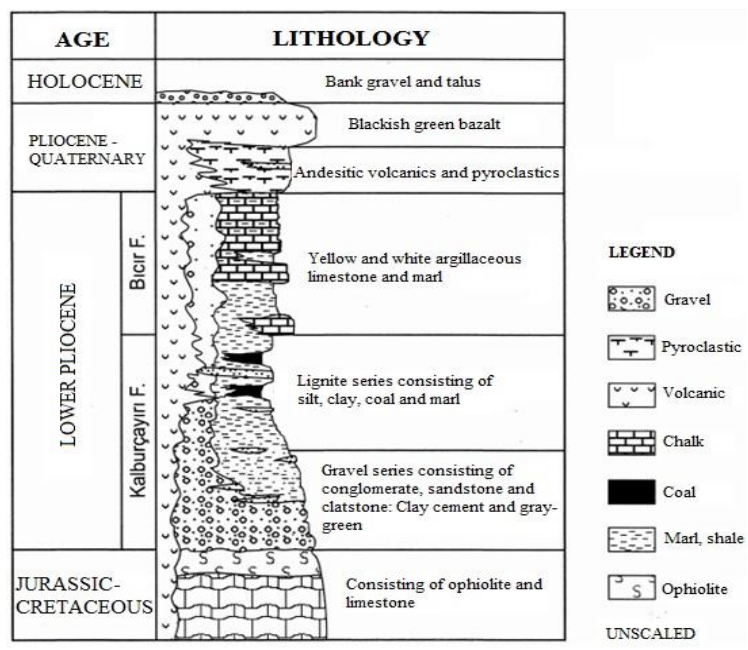

Fig. 2: Litology map of the studied field. 


\section{Rotary Drilling Machines and Bits in the Studied Field}

In the mine, there are four drilling machine that two of them are Reedrill SK 50T and the others are Ingersoll Rand DM 50. In this study, DM 50 machines whose technical properties are given in Table 1 were used since they were operating in those time. After drilling operation, for blasting quintet order and ANFO are preferred [15].

Table 1: Technical properties of drilling machine.

\begin{tabular}{|l|l|}
\hline Ingersoll Rand DM 50 & Rotary or DTH \\
\hline Drilling Method & $149-229 \mathrm{~mm}$ \\
\hline Hole diameter & $222 \mathrm{kN}$ \\
\hline Hydraulic pressure & $9,7 \mathrm{kNm}$ \\
\hline Torque & $65-150 \mathrm{psi}$ \\
\hline Compressor & $7 \mathrm{~m}$ \\
\hline Mast height & $50 \mathrm{~m}$ \\
\hline Max drilling depth & 31,75 tons \\
\hline Weight & $0-130 \mathrm{rpm}$ \\
\hline Rotation speed &
\end{tabular}

Drillers are grouped into two groups as "bits" which are known as drillers with supplying to drill a hole directly and the second group is "expander" which are used in expansion of predrilled holes. The bits which are made of steel casting including special alloys and/or tungsten carbide rotates around themselves under a weight of pressure and cut particles from the rock by type of cutting as scraping and/or grinding. They are classified and named according to their design and material used made of them [4-6].

In this study, two type of bits were used as tricone bits and klaw bits. Their design properties are given in Table 2 and Table 3 and their picture are shown Fig. 2 [13]. The klaw bit used in field is one of the 10 cutting teeth models of brand. It is understood that one of the useful properties of the bit is that wearing cutting teeth can be changed with new ones in a very short time and continue to work. With keeping other parameter constant, these two bits were used in four different fields in DM 50 drilling machines and performance parameters were measured [14].

Table 2: Technical properties of tricone bit.

\begin{tabular}{|l|l|}
\hline \multicolumn{2}{|l|}{ Tricone Bit } \\
\hline IADC Code & 632 \\
\hline Bearing type & Ball bearing \\
\hline Flushing grooves & Jet air \\
\hline Bit type & TCI inserts \\
\hline Connection & $31 / 2 ”$ API Pin \\
\hline Diameter & $171 \mathrm{~mm}$ \\
\hline Weight Advised parameters & $21 \mathrm{~kg}$ \\
\hline \multicolumn{2}{|l}{} \\
\hline W.O.B. & $9185,24-18370,49 \mathrm{Kg}$ \\
\hline Rotation speed & $60-100 \mathrm{rpm}$ \\
\hline
\end{tabular}


Table 3: Technical properties of klaw bit.

\begin{tabular}{|l|l|}
\hline Klaw Bit & One piece 4140 alloy \\
\hline Body & $238,8 \mathrm{~mm}$ \\
\hline Height & $10 x 19$ cutters \\
\hline Cutters & Air \\
\hline Flushing & $41 / 2 \%$ API Pin \\
\hline Connection & $21,8 \mathrm{~kg}$ \\
\hline Weight & $171 \mathrm{~mm}$ \\
\hline Diameter & \multicolumn{2}{|l|}{} \\
\hline Advised parameters & $900-1500$ PSI \\
\hline Feed force & $80-120 \mathrm{rpm}$ \\
\hline Rotation speed
\end{tabular}

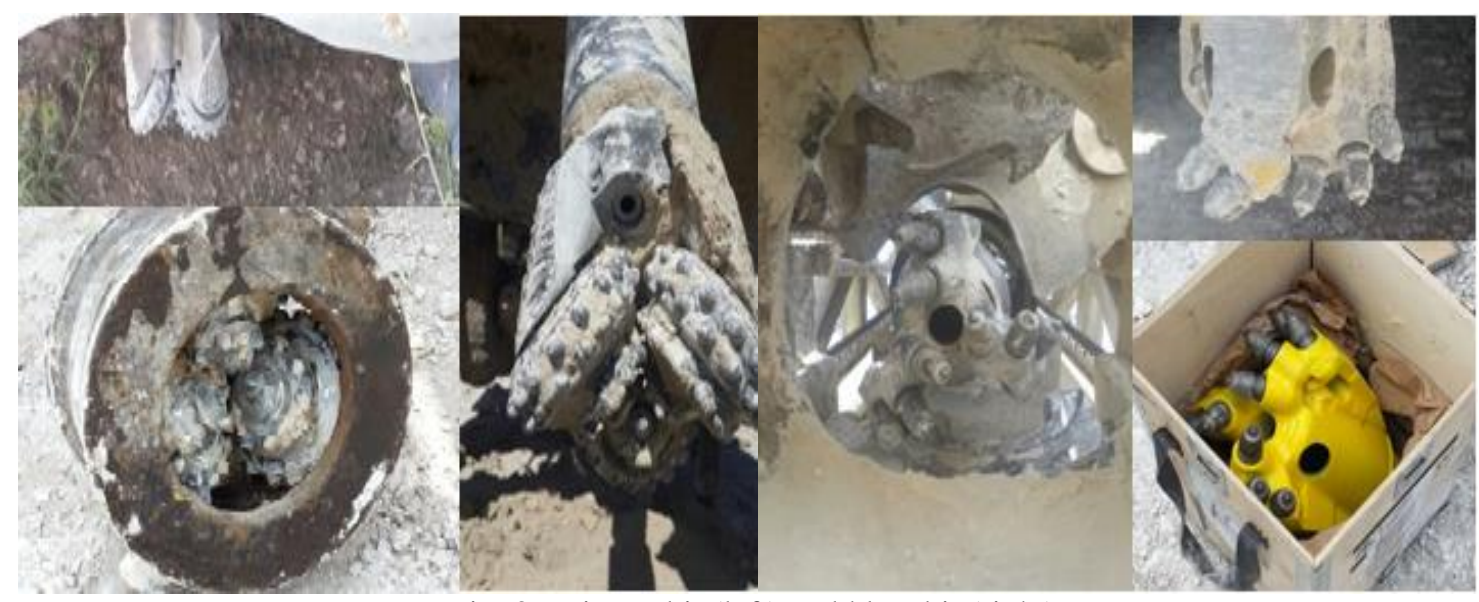

Fig. 3: Tricone bit (left) and klaw bit (right).

The bit used in field is one of the 10 cutting edges models of brand. It is understood that one of the useful properties of the bit is that wearing cutting edges can be changed with new ones in a very short time and continue to work.

\section{Klaw Bit Performance Analysis and Comparison with Tricone Bit}

During the field studies, for both bits, at the same machine and same geological environment, drilling length and drilling time were measured so and then drilling speed (drilling rate) was estimated. While $308 \mathrm{~m}$ was drilled with tricone bit, $553 \mathrm{~m}$ was drilled with klaw bit. All values are instantaneous, times passing without excavating such as welding time, carrying technical equipment, operators waiting and others were excluded. As mentioned before four different geological environment were used. There of them were correspond to 1,2,3 benches starting from surface level of mine. There was also another field placed on intermediate level. In mine all benches are also named according to excavators used in operation time. The designation are listed in parentheses next to number of benches.

Bench 1 (on the $302 \mathrm{PH}$ excavators) is the first level of the mine, the clay tufitte was not observed during measurements, results are given in Table 4 and seen from Fig. 4. Speed of klaw bits is higher than 2,8 times than tricone bits.

Bench 2 (on the marion excavator) is lower level than bench 1 and about $50 \mathrm{~m}$ away from it. Coal is not produced in this bench. A clay tufitte layer is seen in this level chancing thickness between 1-1.5 $\mathrm{m}$ and it is most reducing effect on drilling efficiency. As shown Table 4 and Fig.3 even though rate was declined compared to first bench, klaw bit drilling rate is higher than 1,43 times tricone bit.

Bench 3 (on the 310 marion excavator) is) approximately 300 meters south west of bench 2. After 13-14 meters drilled holes encountered coal. Drilling speed results are given in Table 4 and shown on Fig. 4, klaw bit drilling speed is 2,55 times faster. 
Median bench (near the 306 Marion Excavator) is located approximately 100 meters east of the bench 3 and it is a median level of the pit. After 10-11 meters was drilled is found coal. The clay content as tufitte is high. Klaw bit drilling speed is higher than 1.53 times the tricone bit as shown on Table 4 and Fig. 3.

Table 4: Each of two bit test results.

\begin{tabular}{|l|l|l|l|l|l|l|}
\hline \multirow{2}{*}{} & \multicolumn{2}{l}{ Depth $(\mathbf{m})$} & \multicolumn{2}{l|}{ Time (min) } & \multicolumn{2}{l|}{ Drilling Speed (m/min) } \\
\cline { 2 - 8 } & Tricone & Klaw & Tricone & Klaw & Tricone & Klaw \\
\hline Bench 1 (302 PH) & 91 & 35 & 146 & 20 & 0,623 & 1,750 \\
\hline Bench 2 (308 Marion) & 73,5 & 297,5 & 120 & 339 & 0,63 & 0,878 \\
\hline Bench 3 (310 Marion) & 76 & 161 & 199 & 165 & 0,382 & 0,976 \\
\hline Bench (mid-step) & 67,5 & 60 & 117 & 68 & 0,577 & 0,882 \\
\hline
\end{tabular}

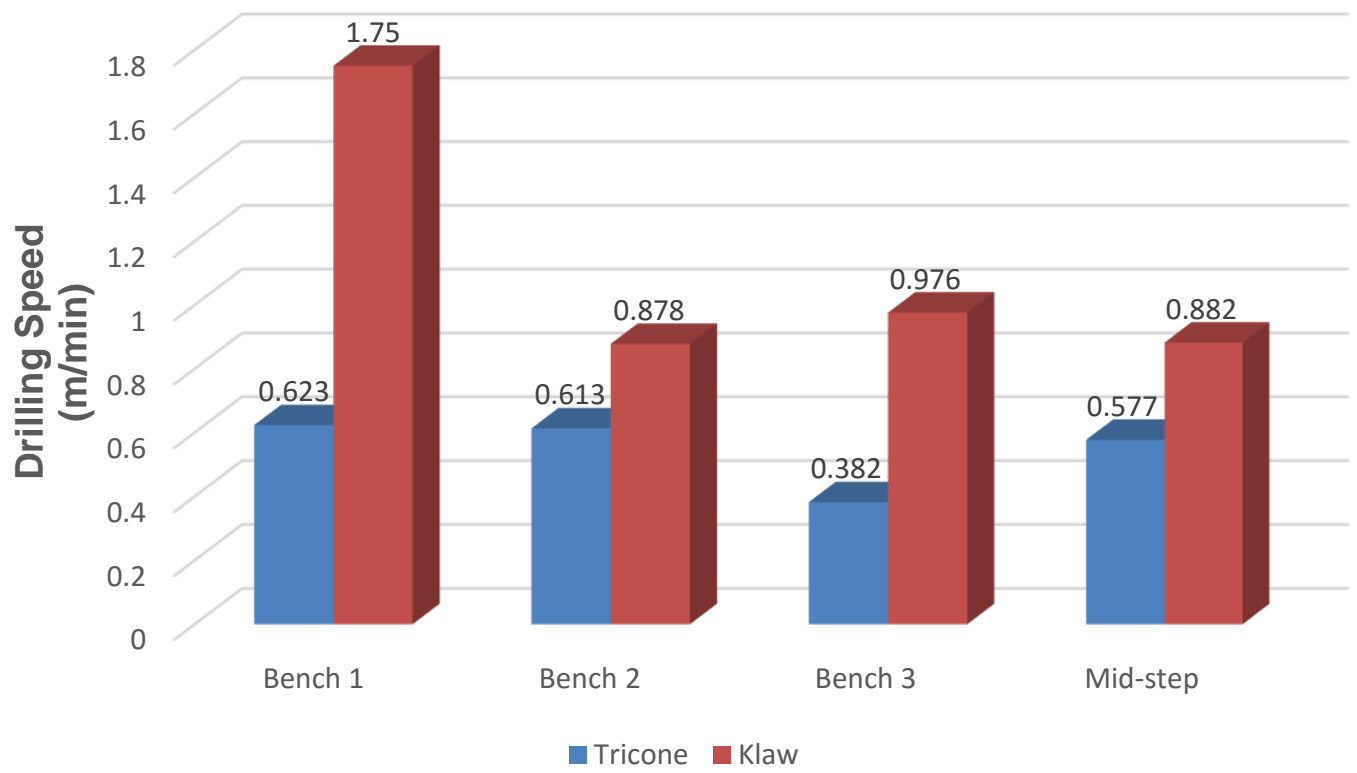

Fig. 4: Comparison of the drill bits speed.

\section{Conclusion}

In a open pit coal mine where is in Kangal town of Sivas County in Turkey, is operated by Demir Export Company. Drilling speed of classical tricone bit and a new technology product named klaw bit was compared in DM 50 rotary drilling machine in this study. Taking by all other parameters as constant, on four different benches which means they have different geological environment respectively, measurements are carried out in this study.

On the all benches, drilling speed of klaw bits was higher than the classical tricone bits. This shows klaw bit, a new generation product, is an important alternative that can be used in rotary drilling machines and it is necessary to continue the trials in different formation. In addition, when drilling operation affect the negatively from clay, water used in the drilling operation. Another solution is sending high pressure air. Therefore, using a stronger air compressor on drilling machine gets higher efficiency and reduces clogging of the bits.

\section{Acknowledgements} data.

We are very grateful to Demir Export for providing working environment and their interest for collecting samples and 


\section{References}

[1] M. J. Fear, "How to Improve Rate of Penetration in Field Operations," in IADC Drilling Conference, Orleans, Louisiana, 1996.

[2] B. Gokhale, Rotary Drilling and Blasting in Large Surface. Balkema: CRC Press, 2010.

[3] M. Bulut, Ö. Acaroğlu, and B. Ergener, "Optimum Drill Bit Selection at TKI Bursa Orhaneli Lignite Plant," in 11. Regional Rock Mechanics Symposium, 269-274, Afyonkarahisar, Turkey, 2014 (in Turkish).

[4] Jimeno, C. L. ve Carcedo, F., J. A., Drilling and blasting of rocks. Imprint Rotterdam. A. A. Balkemae, 1995.

[5] A. Ersoy, Drilling techniques and applications. Adana: Nobel Publishing House, 2008 (in Turkish).

[6] A. Yalçın, and B. ve Yalçın, Drilling methods and applications. TMMOB, İstanbul 5th edition, 2011, (in Turkish).

[7] O. Yaralı and S. Kahraman, "The Drillability Assessment of Rocks Using the Different Brittleness Values," Tunnelling and Underground Space Technology, vol. 26, pp. 406-414, 2010.

[8] O. Saeidi, O. R. Torabi, M. Ataei, and J. Rostami, "A Stochastic Penetration Rate Model for Rotary Drilling in Surface Mines,” International Journal of Rock Mechanics \& Mining Sciences, vol. 68, pp. 55-65, 2014.

[9] M. Ataei, R. Kakaie, M. Ghavidel, and O. Saeidi, "Drilling Rate Prediction Of An Open Pit Mine Using The Rock Mass Drillability Index," International Journal Of Rock Mechanics \& Mining Sciences, vol. 73, pp. 130-138, 2015.

[10] A. Babatunde and B. W. Ademola, "Discontinuities Effect on Drilling Condition and Performance of Selected Rocks in Nigeria," International Journal of Mining Science and Technology, vol. 24, pp. 603-608, 2014.

[11] O. Saeidi, J. Rostami, M. Ataei, and S. R. Torabi, "Use of Digital Image Processing Techniques for Evaluating Wear of Cemented Carbide Bits in Rotary Drilling," Automation in Construction, vol. 44, pp. 140-151, 2014.

[12] R. Altındağ, "The Evaluation of Rock Brittleness Concept on Rotary Blast Hole Drills," The Journal of the South African Institute of Mining and Metallurgy, pp. 61-66, 2002.

[13] G. Hareland, A. Wu, B. Rashidi, and J. A. James, "A New Drilling Rate Model for Tricone Bits and Its Application to Predict Rock Compressive Strength," in 5th U.S.-Canada Rock Mechanics Symposium, Utah, 2010.

[14] S. Demirdağ, N. Sengun, İ. Uğur, T. Efe, D. Akbay, and R. Altındağ, "Variation of Vertical and Horizontal Drilling Rates Depending on Some Rock Properties in The Marble Quarries," International Journal of Mining Science and Technology, vol. 24, pp. 269-273, 2014.

[15] Atlas Copco, "Klaw Bit 9" K31L Catalogue", "Running Procedure", "PDC and Klaw Brochure", 2015.

[16] U. Caliskan "Klaw bit performance analysis and compared with tricone bits in a Coal Mine of Demir Export, Graduation Project," Mining Engineering Department, Istanbul Technical University, Turkey, 2016.

[17] Ö. ve Saraç Şen, C., "Geology and Evaluation of Kalburçayın (Kangal, Sivas) Lignite Basin by Block Kriging," Geological Bulletin of Turkey, vol. 43, no. I, pp. 21-31, 2000. 